\title{
The influence of kinesio taping on trunk and lower extremity motions during different landing tasks: implications for anterior cruciate ligament injury
}

\author{
Bahram Sheikhi ${ }^{1}$, Amir Letafatkar ${ }^{2 *} \mathbb{0}$, Jennifer $\operatorname{Hogg}^{3}$ and Esmaiel Naseri-Mobaraki ${ }^{4}$
}

\begin{abstract}
Purpose: The purpose of the study was to investigate the influence of a 72-h KT application on trunk and lower extremity kinematics during different landing tasks.

Methods: Twenty-nine competitive male athletes participated in this study. The sum of knee valgus and lateral trunk lean, symmetry index (SI), and peak angles of lateral trunk lean, hip flexion, knee abduction and flexion were assessed for all participants during single-leg drop landing (SLDL), single-leg vertical drop jump (SLVDJ), vertical drop jump (DLVDJ), and double leg forward jump (DLFJ), at baseline and seventy-two hours following KT application.
\end{abstract}

Results: The KT application resulted in more knee flexion and abduction, sum of knee valgus and lateral trunk lean as compared with the non-KT condition during SLDL $(P<0.05)$. Nonetheless, there were no differences in $\mathrm{Sl}$, maximum angle of the lateral trunk lean during SLDL, SLVDJ, nor hip flexion, knee abduction, and flexion during DLVDJ, and DLFJ tasks $(P>0.05)$.

Conclusions: The research findings suggest that KT after 72-h application may improve knee abduction and sum of knee valgus and lateral trunk lean during SLDL, knee flexion during SLDL and SLVDJ in individuals displaying risky single-leg kinematics. Therefore, KT application may marginally improve high-risk landing kinematics in competitive male athletes.

Level of evidence: Level III.

Keywords: Kinesio tape, Anterior cruciate ligament, Knee, Landing, Joint kinematics

\section{Introduction}

Anterior cruciate ligament (ACL) injuries frequently occur in non-contact situations such as landing [12, 22]. In order to assess ACL injury risk and develop potential preventive strategies, researchers have typically measured biomechanical characteristics during various landing tasks [17].

\footnotetext{
*Correspondence: letafatkaramir@yahoo.com

${ }^{2}$ Department of Biomechanics and Sports Injury, Faculty of Physical

Education and Sports Sciences, Kharazmi University, Tehran, Iran

Full list of author information is available at the end of the article
}

Poor sagittal and frontal plane movement patterns are believed to increase knee injury risk in athletes [10, 25]. Specifically, dynamic malalignment patterns comprised of greater ipsilateral trunk lean, hip adduction, hip internal rotation, knee valgus (KV) and tibial internal or external rotation, in addition to less hip and knee flexion, have been associated with greater knee joint loading and subsequently higher non-contact ACL injury risk during landing tasks. Characterized by an erect landing posture and less sagittal plane trunk displacement, stiff landings result in greater ground reaction forces [12], external knee abduction and flexion moments, and smaller 
external hip flexion moments $[8,10]$. In the sagittal plane, the trunk and lower extremity work in a coupled fashion to attenuate landing forces, such that greater motion at one joint is typically accompanied by corresponding motion at adjacent joints, allowing for improved force absorption $[9,12]$. In the frontal plane, greater KV displacement is a primary predictor of non-contact ACL injury risk [12]. A combination of increased two-dimensional (2D) measured KV and ipsilateral trunk lean was associated with increased external peak knee abduction moment during a single leg vertical drop jump (SLVDJ). Increased lateral trunk lean causes the ground reaction vector to pass lateral to the knee joint, thereby creating an external knee abduction moment. Greater KV allows the ground reaction force (GRF) to exert even greater frontal plane torque upon the knee joint $[8,10]$. In addition to intra-limb kinematics, inter-limb asymmetries are also shown to increase the occurrence of sport-related injuries. Reduced asymmetry, specifically in regards to knee flexion, knee abduction, and hip flexion, can prevent lower extremity injury [38].

While it is accepted that dynamic trunk, hip, and knee alignment influence one's risk for ACL injury [4, $9,40]$, it is largely unknown if kinesio taping (KT) may improve high-risk kinematics. KT is an elastic therapeutic tape used to prevent and treat sports injuries and various musculoskeletal conditions [21, 43]. KT has several positive effects: improving lymphatic flow by increasing interstitial space, supporting muscles and joints, and correcting articular malalignment and function [21, 28]. Moreover, KT is known for improving function, stability, proprioception [16], and force production of the muscle
[21, 35]. Also, through tactile input, KT has been able to stimulate cutaneous mechanoreceptors and alter motoneurons [6].

According to the author's knowledge, no study has tried to examine the sum of knee valgus and lateral trunk lean, lateral trunk lean, knee abduction, hip and knee flexion, and asymmetry of landing tasks after KT application. Using methods such as KT may help correct dynamic malalignment patterns, and reduce knee injury risk [5, 30, 32].

Investigating different landing tasks can enhance our understanding of the influence of $\mathrm{KT}$ on motion and injury risk. Accordingly, this study's aim was to investigate the influence of KT on trunk, hip and knee motions during a single-leg drop landing (SLDL), SLVDJ, double leg vertical drop jump (DLVDJ), and double leg forward jump (DLFJ) tasks. The primary hypothesis was that KT would improve peak sagittal and frontal plane angles of the trunk, hip and knee during SLDL, SLVDJ, DLVDJ and DLFJ.

\section{Materials and methods Study design and participants}

A pretest-posttest design was used in the current study. Trunk, hip and knee kinematics were assessed during SLDL, SLVDJ, DLVDJ and DLFJ. Following baseline testing, KT was applied to gastrocnemius, biceps femoris, semitendinosus, semimembranosus, vastus lateralis, vastus medialis, rectus femoris, gluteus medius, rectus abdominis, and erector spinae muscles (Fig. 1). Each participant returned for follow-up testing $72 \mathrm{~h}$ later.

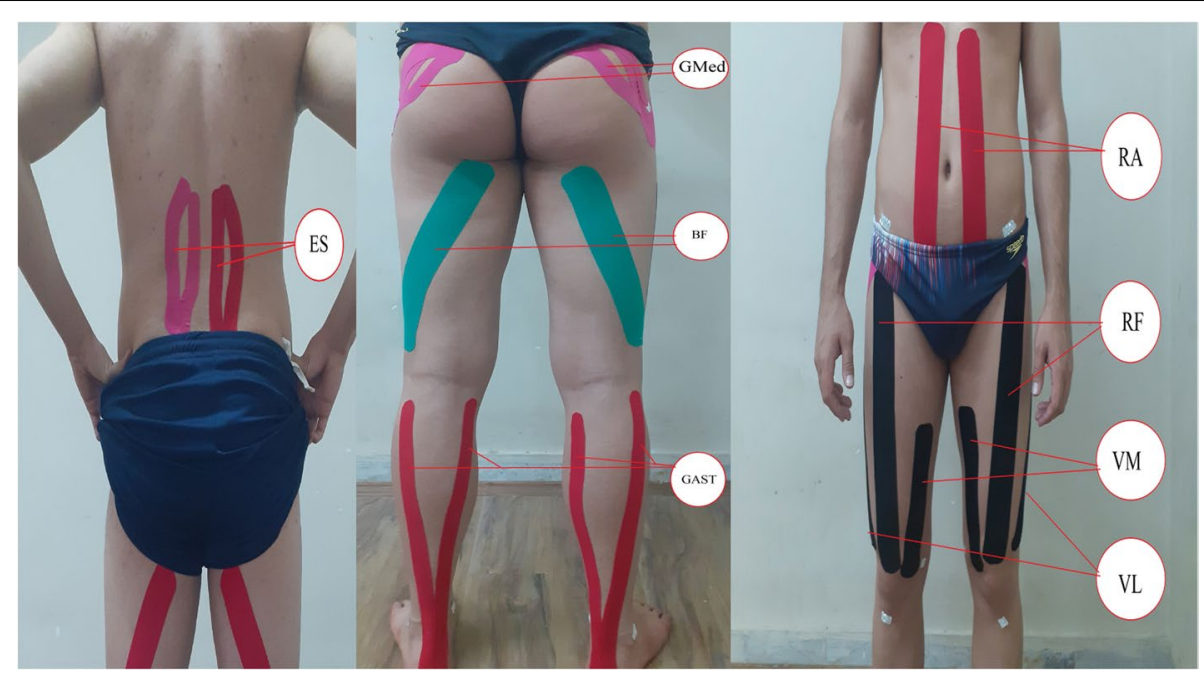

Fig. 1 Kinesio taping applications: gastrocnemius (GAST), biceps femoris (BF), vastus lateralis (VL), vastus medialis (VM), rectus femoris (RF), gluteus medius (GMed), rectus abdominis (RA), and erector spinae (ES) muscles 
Twenty-nine competitive males (mean $\pm \mathrm{SD}$, $23.2 \pm 2.1 \quad$ years; $\quad 185.8 \pm 7.0 \quad \mathrm{~cm} ; \quad 77.0 \pm 7.3 \quad \mathrm{~kg}$; $\mathrm{KV}=13.1 \pm 1.9$ degrees) were included in this study. Only male participants were included to avoid sex-specific differences in neuromuscular performance [31]. Six participants were right limb dominant and 23 were left limb dominant, as determined by asking participants which leg they preferred to land on following a jump. Participants had an average of $8.4 \pm 2.1$ years of experience in their respective jumping and multidirectional sports ( 8 soccer athletes, 10 basketball athletes, 5 handball athletes, and 6 volleyball athletes). Prior to data collection, this study had been approved by the research ethics committee of the faculty of physical education and sport science of the Tarbiat Modarres University. The study was performed in accordance with the ethical standards in the World Medical Association Declaration of Helsinki (2002). Ethical approval was obtained from the Ethical Committee of the Medical Faculty of the Tarbiat Modarres and the ethical standards in sport and exercise science research were respected.

To be eligible to participate, each participant was required to meet the following criteria: 18-26 years of age, no history of surgery in the lower extremity in the previous six months, no history of non-corrected neurological, vestibular, visual and/or hearing impairments, no musculoskeletal injury that could interfere with or contraindicate the assessment procedures [7,
40], and must have had no allergy to adhesive material [5] nor any other conditions that prevent them from participating at the maximal effort in sporting activities [4], Additionally, KV of more than 10 degrees during a single leg squat test (SLS) was required to participate in this study. The SLS test was used in this study based on the protocol introduced by Ugalde et al. [41]. One hundred-three athletes were assessed for eligibility; which 74 athletes did not meet inclusion criteria.

\section{Procedures \\ KT application}

Kinesio tape (Kinesio Tex Gold ${ }^{\mathrm{TM}}$, FP, $5 \mathrm{~cm}$ wide) was used in this study according to the technique described by Kase et al. [21], and was applied with $50 \%-75 \%$ tape tension. KT was applied to muscles (gastrocnemius, biceps femoris, vastus lateralis, vastus medialis, rectus femoris, gluteus medius, rectus abdominis, and erector spinae) that show the greatest impact on trunk, hip and knee motion during landing (Fig. 1, Table 1). In order to standardize tension during the KT application, the distances between the origin and insertion of all participants' muscles were measured. Prior to the adhesive KT application, the skin was first cleaned at the site of application using an alcohol 70 GL prep pad, and excess hair was trimmed so as to ensure $\mathrm{KT}$ adherence. Furthermore, the participants' skin sensitivity was tested with a KT test patch over a period of $24 \mathrm{~h}$ prior to the study. All strips were bilaterally applied to the

Table 1 KT application was applied in the following order

\begin{tabular}{|c|c|}
\hline Muscles & KT application \\
\hline Gastrocnemius & $\begin{array}{l}\text { The KT was split into a Y-strip so that each side could be longitudinally taped along with origin of the medial and lateral gastrocne- } \\
\text { mius muscles. Both the proximal ends of the Y-strip were placed, without tension, } 4 \mathrm{~cm} \text { below the popliteal line with the ankle } \\
\text { in the neutral position. The proximal half of the strip was then stretched and placed on the calf up to the marked midpoint with } \\
\text { the participant's ankle at maximum dorsiflexion. The distal half of the strip was also stretched and placed from the midpoint to } \\
\text { the upper part of the calcaneus posterior tuberosity with the participants ankle still at maximum dorsiflexion, and distal end of } \\
\text { the Y-strip was then placed, without tension, with the ankle back in neutral position [19] }\end{array}$ \\
\hline Biceps Femoris & $\begin{array}{l}\text { As regards biceps femoris KT, the participant was positioned side lying with the knee in extension, the hip in flexion, the hip medi- } \\
\text { ally rotated, and the contralateral leg slightly bent for stability. KT was applied from the ischial tuberosity to the posterior region } \\
\text { of the fibular head [31] }\end{array}$ \\
\hline Quadriceps & $\begin{array}{l}\text { KT was applied on quadriceps muscle, from the proximal to the distal [12]. Also, it was applied to the RF from } 10 \mathrm{~cm} \text { below the } \\
\text { anterior superior iliac spine (ASIS) to the upper edge of the patella [20]. The strip was fixed on the VL muscle from the greater } \\
\text { trochanter to the lateral patella edge. For the VM muscle, KT was applied to the middle third from the medial region of the thigh } \\
\text { to the medial patella edge. This application was performed with participants standing on one foot, with the hip of the dominant } \\
\text { limb at } 0^{\circ} \text { and knee flexed at } 90^{\circ}[17] \text {. The individuals were requested to perform a maximal extension of their knee in order to } \\
\text { obtain length measurements, and to make KT final adjustments prior to its application }\end{array}$ \\
\hline Gluteus Medius & $\begin{array}{l}\text { For the gluteus medius, KT was applied from iliac crest to GT in side lying position. Participants were asked to take the side-lying } \\
\text { position with } 90^{\circ} \text { hip flexion, adduction and internal rotation. Y strip was used from insertion to origin. Base of the Y strip was } \\
\text { applied on the lateral surface of the GT with no tension. Anterior tail was applied towards the ASIS with light or paper off tension } \\
\text { and the last 1-2 inches with no tension. Posterior tail was applied towards PSIS with a similar tension mentioned above [12, 16] }\end{array}$ \\
\hline Erector Spinae & $\begin{array}{l}\text { The tape was bilaterally placed over the erector spinae muscles, parallel to the spinous processes of the lumbar vertebrae [44], } \\
\text { starting near the posterior superior iliac crest [45] }\end{array}$ \\
\hline Rectus Abdominis & $\begin{array}{l}\text { Two pieces of tape were longitudinally applied on the rectus abdominis from the level of the xiphoid process to the pubic sym- } \\
\text { physis level [46] }\end{array}$ \\
\hline
\end{tabular}


trunk and lower extremity muscles by the same trained researcher.

\section{Landing tasks}

Prior to the tests, the participants executed a standardized warm-up protocol consisting of a series of doubleleg squats $(2 \times 8$ repetitions $)$ and double-leg maximum jumps $(2 \times 5$ repetitions), followed by calf-stretching with a straight and bent knee [37]. Ten minutes were allotted to each participant to perform self-directed stretches and warm-ups. Furthermore, the participants were allowed to familiarize themselves with the test procedures by performing two or three practice repetitions before each test.

The participants completed four tests: SLDL, SLVDJ, DLVDJ and DLFJ. A single tester provided the participants with all the instructions regarding all four tests. Both legs were tested in the single-leg tests. The tests were also randomly ordered. All participants completed three practice trials and three successful test trials of each task. At least 60 s' rest was given between each repetition and two minutes' rest after each task to minimize fatigue. All measurements were conducted in the university biomechanics laboratory.

\section{Single-Leg Drop Landing (SLDL)}

Participants performed SLDL from a $30-\mathrm{cm}$ box [42]. After landing, this position was maintained for five seconds. A trial was not deemed valid if the other leg touched the ground or if the participants was clearly out of balance or fell during the test.

\section{Single-Leg Vertical Drop Jump (SLVDJ)}

Each participant performed a SLVDJ on his dominant leg. A SLVDJ consisted of dropping from a 10-cm box, landing on one limb, completing an immediate maximal vertical jump, and landing again [37]. A trial was deemed invalid if the participant jumped off the box instead of just dropping, if the other leg touched the ground or if the participant was clearly out of balance or fell during the test.

\section{Double Leg Vertical Drop Jump (DLVDJ)}

As for the DLVDJ, the participants were instructed to drop from a $30-\mathrm{cm}$ height box, land on both limbs, and immediately perform a maximal vertical jump $[19,37,39]$. A trial was not considered valid if the participant lost balance or fell during the performance.

\section{Double Leg Forward Jump (DLF)}

For the DLFJ, a 30-cm box was placed at a distance equal to $50 \%$ of the participant's height from the front edge of the force plates. From this distance, the participant jumped onto a set of plates with both feet simultaneously, and subsequently performed a maximum vertical jump [4]. A trial was not deemed valid if the participant lost balance or fell during the performance.

\section{Data Reduction \\ Two-dimensional video analysis}

Different landing tasks were captured with two standard digital video cameras (Sony HDR-PJ675). The video cameras were placed on tripods perpendicular to the sagittal and frontal planes, at a height of $0.6 \mathrm{~m}$ and a distance of $3.5 \mathrm{~m}$ from the force plates. Also, markers were bilaterally placed on the acromioclavicular (AC) joint, manubrium sterni, anterior superior iliac spine (ASIS), greater trochanter (GT), medial and lateral femoral epicondyles, and medial and lateral malleolus $[10,18]$.

In the frontal plane, lateral trunk lean was defined as the angle formed by vertical and a line from the ipsilateral ASIS to the manubrium sterni. Knee abduction angle was delimited as the angle formed by a segmented line from the ASIS to the knee joint center to the ankle joint center. In the sagittal plane, knee flexion angle was defined as the angle formed by a segmented line from the GT to the lateral femoral epicondyle to the lateral malleolus. Hip flexion angle was defined as the angle formed by a segmented line from the lateral femoral epicondyle to the GT to the AC joint [9]. The video recordings were analyzed using the Kinovea software (version 0.8.15). The ankle joint center was defined as the mid-point of the lateral and medial malleolus markers, and the knee joint center was described as the mid-point of the lateral and medial femoral epicondyle markers [1]. Joint angles were averaged across the three trials and used for statisti$\mathrm{cal}$ analysis. The point of maximum knee flexion during landing tasks was visually determined in Kinovea and was defined as the time point where no downward or upward movement occurred at the knee. At the point of maximal knee flexion, a digital picture of each trial was taken. All angles were drawn on the same digital picture and measured by a single investigator blinded to testing session.

\section{Symmetry Index (SI)}

As regards SLDL and SLVDJ, the degree of asymmetry between the dominant and non-dominant limb was then computed using the SI (Eq. 1), [38].

$$
\text { Symmetry Index }=\frac{2(\text { dominant limb }- \text { non dominant limb })}{(\text { dominant limb }+ \text { non dominant limb })} \times 100 \%
$$




\section{Statistical analyses}

An a priori power analysis was performed using $\mathrm{G}^{*}$ Power software (version 3.1.9.2, written by Franz Faul, university Kiel, Germany). Given a medium effect size of 0.25 , alpha level of 0.05 , and a power of 0.8 , a minimum of 24 participants was needed for this study.

Normality of variables were assessed using the Shapiro Wilk Test. Paired t-tests were performed to determine the influence of $\mathrm{KT}$ on the sum of knee valgus and lateral trunk lean, SI, and maximum angles of lateral trunk lean, hip flexion, knee abduction and knee flexion during the different landing tasks. Furthermore, magnitudes of the differences were examined using Cohen's $d$ effect size (ES), and were interpreted as follows: $<0.35-$ trivial; 0.35-0.8-small; 0.8-1.5-moderate; $>1.5$ - large [3]. Change percentages were also calculated to compare follow-up testing with baseline testing.

Statistical significance was set a priori at $\leq 0.05$. Data were analyzed using SPSS (version 16.0; SPSS Inc., Chicago, IL).

\section{Results}

\section{Knee abduction}

For knee abduction, within-subject differences for SLDL in the dominant leg $(\mathrm{ES}(95 \% \mathrm{CI})=0.65(0.24$ to 1.05$)$;
$P=0.022)$ and non-dominant leg $(\mathrm{ES}(95 \% \mathrm{CI})=0.61(0.21$ to 1.00$) ; P=0.014$ ) were significant. SLVDJ (dominant leg: ES $(95 \% \mathrm{CI})=-0.42(-0.80$ to -0.04$) ; P=0.083$; non-dominant leg: $\mathrm{ES}(95 \% \mathrm{CI})=0.14(-0.23$ to 0.50$) ; P=0.678)$, DLVDJ $(E S(95 \% C I)=0.03(-0.34$ to 0.39$) ; P=0.926)$ and DLFJ $(E S(95 \% C I)=-0.25(-0.62$ to 0.12$) ; P=0.204)$, differences were not significant (Tables 2 and 3 ).

\section{Knee flexion}

During SLDL and SLVDJ, the KT application resulted in more knee flexion as compared to the non-KT condition. The within-subject difference was significant for SLDL (dominant leg: ES $(95 \% \mathrm{CI})=-0.45(-0.83$ to -0.07$) ; P=0.018$; non-dominant leg: ES $(95 \% \mathrm{CI})=-0.46 \quad(-0.84$ to -0.07$)$; $P=0.031)$ and SLVDJ (dominant leg: ES $(95 \% \mathrm{CI})=-0.57$ (-0.96 to -0.18$) ; \quad P=0.034$; non-dominant leg: ES $(95 \% \mathrm{CI})=-0.45(-0.83$ to -0.07$) ; P=0.040)$. Conversely, in the DLVDJ (ES $(95 \% \mathrm{CI})=-0.08(-0.45$ to 0.28$) ; P=0.690)$ and DLFJ (ES $(95 \% \mathrm{CI})=-0.15(-0.51$ to 0.21$) ; P=0.550)$, significant differences were not observed (Tables 2 and 3 ).

\section{Hip flexion}

For hip flexion, within-subject differences were not significant for SLDL (dominant leg; ES $(95 \% \mathrm{CI})=-0.53$

Table 2 Within-group changes in peak angles of knee abduction, knee flexion, hip flexion, lateral trunk lean, sum of knee valgus and lateral trunk lean during SLDL, SLVDJ tasks

\begin{tabular}{|c|c|c|c|c|c|c|c|}
\hline $\begin{array}{l}\text { Landing Characteristic } \\
\left({ }^{\circ}\right)\end{array}$ & Task & Landing Leg & Without KT (Baseline) $^{\alpha}$ & With KT ${ }^{a}$ & Pvalue & $\begin{array}{l}\text { Effect size }^{\dagger} \text { and } 95 \% \\
\text { Confidence Interval } \\
\text { (Lower limit -Upper limit) }\end{array}$ & $\begin{array}{l}\text { Change Relative } \\
\text { to } \text { Baseline }^{\ddagger}(\%)\end{array}$ \\
\hline \multirow[t]{4}{*}{ Knee abduction } & \multirow[t]{2}{*}{ SLDL } & Dominant & $169.0 \pm 6.3$ & $172.0 \pm 4.6$ & $0.022^{*}$ & 0.65 (0.24 to 1.05$)$ & $\uparrow 1.8$ \\
\hline & & Non-dominant & $168.3 \pm 4.8$ & $171.7 \pm 5.6$ & $0.014^{*}$ & 0.61 (0.21 to 1.00$)$ & $\uparrow 2.0$ \\
\hline & \multirow[t]{2}{*}{ SLVDJ } & Dominant & $169.0 \pm 5.7$ & $166.4 \pm 6.3$ & 0.083 & $-0.42(-0.80$ to -0.04$)$ & $\downarrow 1.6$ \\
\hline & & Non-dominant & $167.5 \pm 8.2$ & $168.3 \pm 6.2$ & 0.678 & $0.14(-0.23$ to 0.50$)$ & $\uparrow 0.5$ \\
\hline \multirow[t]{4}{*}{ Knee flexion } & \multirow[t]{2}{*}{ SLDL } & Dominant & $103.3 \pm 7.1$ & $98.8 \pm 9.9$ & $0.018^{*}$ & $-0.45(-0.83$ to -0.07$)$ & $\downarrow 4.3$ \\
\hline & & Non-dominant & $96.4 \pm 8.9$ & $91.6 \pm 10.5$ & $0.031^{*}$ & $-0.46(-0.84$ to -0.07$)$ & $\downarrow 5.0$ \\
\hline & \multirow[t]{2}{*}{ SLVDJ } & Dominant & $114.2 \pm 9.0$ & $108.6 \pm 9.7$ & $0.034^{*}$ & $-0.57(-0.96$ to -0.18$)$ & $\downarrow 4.9$ \\
\hline & & Non-dominant & $112.9 \pm 8.4$ & $109.6 \pm 7.2$ & $0.040^{*}$ & $-0.45(-0.83$ to -0.07$)$ & $\downarrow 2.9$ \\
\hline \multirow[t]{4}{*}{ Hip flexion } & \multirow[t]{2}{*}{ SLDL } & Dominant & $87.4 \pm 13.2$ & $80.5 \pm 12.9$ & 0.060 & $-0.53(-0.91$ to -0.14$)$ & $\downarrow 7.8$ \\
\hline & & Non-dominant & $94.6 \pm 21.9$ & $91.5 \pm 9.2$ & 0.553 & $-0.34(-0.71$ to 0.04$)$ & $\downarrow 3.3$ \\
\hline & \multirow[t]{2}{*}{ SLVDJ } & Dominant & $124.9 \pm 14.2$ & $119.9 \pm 6.1$ & 0.098 & $-0.82(-1.24$ to -0.40$)$ & $\downarrow 4.0$ \\
\hline & & Non-dominant & $132.5 \pm 11.3$ & $125.9 \pm 21.3$ & 0.152 & $-0.31(-0.68$ to 0.07$)$ & $\downarrow 4.9$ \\
\hline \multirow[t]{4}{*}{ Lateral trunk lean } & \multirow[t]{2}{*}{ SLDL } & Dominant & $9.1 \pm 5.1$ & $9.6 \pm 6.7$ & 0.619 & 0.08 (-0.29 to 0.44$)$ & $\uparrow 5.6$ \\
\hline & & Non-dominant & $11.1 \pm 6.1$ & $11.2 \pm 8.0$ & 0.924 & 0.01 (-0.35 to 0.38$)$ & $\uparrow 1.0$ \\
\hline & \multirow[t]{2}{*}{ SLVDJ } & Dominant & $8.3 \pm 5.4$ & $8.4 \pm 5.5$ & 0.850 & 0.02 (-0.34 to 0.38$)$ & $\uparrow 1.3$ \\
\hline & & Non-dominant & $7.9 \pm 4.8$ & $6.6 \pm 4.4$ & 0.199 & $-0.29(-0.66$ to 0.09$)$ & $\downarrow 16.1$ \\
\hline \multirow{4}{*}{$\begin{array}{l}\text { Sum of knee valgus and } \\
\text { lateral trunk lean }\end{array}$} & \multirow[t]{2}{*}{ SLDL } & Dominant & $178.1 \pm 7.8$ & $181.6 \pm 9.4$ & $0.033^{*}$ & $0.37(-0.004$ to 0.75$)$ & $\uparrow 2.0$ \\
\hline & & Non-dominant & $179.3 \pm 8.2$ & $182.9 \pm 11.6$ & $0.044^{*}$ & 0.31 (-0.07 to 0.68$)$ & $\uparrow 2.0$ \\
\hline & \multirow[t]{2}{*}{ SLVDJ } & Dominant & $177.3 \pm 6.9$ & $174.8 \pm 7.9$ & 0.097 & $-0.32(-0.69$ to 0.05$)$ & $\downarrow 1.4$ \\
\hline & & Non-dominant & $175.3 \pm 8.9$ & $174.9 \pm 7.5$ & 0.860 & $-0.05(-0.41$ to 0.31$)$ & $\downarrow 0.2$ \\
\hline
\end{tabular}


Table 3 Peak angles of knee abduction, knee flexion and hip flexion during DLVDJ, DLFJ tasks

\begin{tabular}{|c|c|c|c|c|c|c|}
\hline Landing Characteristic $\left({ }^{\circ}\right)$ & Task & Without KT (Baseline) ${ }^{a}$ & With $\mathbf{K T}^{a}$ & Pvalue & $\begin{array}{l}\text { Effect size }{ }^{\dagger} \text { and } 95 \% \text { Confidence } \\
\text { Interval (Lower limit -Upper limit) }\end{array}$ & $\begin{array}{l}\text { Change Relative } \\
\text { to Baseline }{ }^{\ddagger}(\%)\end{array}$ \\
\hline \multirow[t]{2}{*}{ Knee abduction } & DLVDJ & $169.4 \pm 6.3$ & $169.5 \pm 4.8$ & 0.926 & $0.03(-0.34$ to 0.39$)$ & $\uparrow 0.1$ \\
\hline & DLFJ & $168.5 \pm 5.0$ & $166.1 \pm 9.6$ & 0.204 & $-0.25(-0.62$ to 0.12$)$ & $\downarrow 1.4$ \\
\hline \multirow[t]{2}{*}{ Knee flexion } & DLVDJ & $94.3 \pm 9.2$ & $93.3 \pm 11.0$ & 0.690 & $-0.08(-0.45$ to 0.28$)$ & $\downarrow 1.0$ \\
\hline & DLFJ & $96.7 \pm 11.9$ & $94.8 \pm 12.5$ & 0.550 & $-0.15(-0.51$ to 0.21$)$ & $\downarrow 2.0$ \\
\hline \multirow[t]{2}{*}{ Hip flexion } & DLVDJ & $101.3 \pm 22.2$ & $106.0 \pm 24.1$ & 0.481 & $0.20(-0.17$ to 0.56$)$ & $\uparrow 4.7$ \\
\hline & DLFJ & $101.7 \pm 21.1$ & $95.2 \pm 13.2$ & 0.128 & $-0.49(-0.87$ to -0.10$)$ & $\downarrow 6.4$ \\
\hline
\end{tabular}

Abbreviation: ${ }^{a}$, Values stands for Mean \pm SD; DLVD J Double leg vertical drop jump, DLFJ Double leg forward jump, KT Kinesio taping; $\dagger$, Cohen's d; $\neq$, percent change relative to baseline $(\downarrow$ decrease, $\uparrow$ increase)

(-0.91 to -0.14$) ; P=0.060$, and non-dominant leg; ES $(95 \% \mathrm{CI})=0.34(-0.71$ to 0.04$) ; P=0.553)$, SLVDJ (dominant leg; ES $(95 \% \mathrm{CI})=-0.82(-1.24$ to -0.40$) ; P=0.098$, and non-dominant leg; ES $(95 \% \mathrm{CI})=-0.31(-0.68$ to 0.07$)$; $P=0.152)$, DLVDJ (ES $(95 \% \mathrm{CI})=0.20(-0.17$ to 0.56$)$; $P=0.481)$ or DLFJ (ES $(95 \% \mathrm{CI})=-0.49(-0.87$ to -0.10$)$; $P=0.128$ ) (Tables 2 and 3 ).

\section{Lateral trunk lean}

For lateral trunk lean, within-subject differences for SLDL (dominant leg: ES $(95 \% \mathrm{CI})=0.08 \quad(-0.29$ to $0.44) ; P=0.619$; non-dominant leg: $\mathrm{ES}(95 \% \mathrm{CI})=0.01$ $(-0.35$ to 0.38$) ; P=0.924)$ and SLVDJ (dominant leg: ES $(95 \% \mathrm{CI})=0.02(-0.34$ to 0.38$) ; P=0.924$; non-dominant leg; ES $(95 \% \mathrm{CI})=-0.29(-0.66$ to 0.09$) ; P=0.850)$ were not significant (Table 2).

\section{Sum of knee valgus and lateral trunk lean}

For the sum of knee valgus and lateral trunk lean, within-subject differences were deemed significant for SLDL (dominant leg; ES $(95 \% \mathrm{CI})=0.37(-0.004$ to $0.75) ; P=0.033)$; non-dominant leg: ES $(95 \% \mathrm{CI})=0.31$ $(-0.07$ to 0.68$) ; P=0.044)$, but were not significant for SLVDJ (dominant leg: ES $(95 \% \mathrm{CI})=-0.32(-0.69$ to 0.05$)$;
$P=0.097$; non-dominant leg: ES $(95 \% \mathrm{CI})=-0.05(-0.41$ to $0.31) ; P=0.860$ ) (Table 2).

\section{SI}

Within-subject SI differences were not significant for knee abduction (SLDL: ES $(95 \% \mathrm{CI})=-0.06(-0.42$ to 0.30$)$; $P=0.850$; SLVDJ: ES $(95 \% \mathrm{CI})=-0.61(-1.00$ to -0.21$)$; $P=0.089)$, hip flexion (SLDL: ES $(95 \% \mathrm{CI})=0.34(-0.03$ to $0.72) ; P=0.161$; SLVDJ: ES $(95 \% \mathrm{CI})=0.13(-0.24$ to 0.49$)$; $P=0.615)$, knee flexion (SLDL: ES $(95 \% \mathrm{CI})=0.04(-0.32$ to 0.40$) ; P=0.833$; SLVDJ: ES $(95 \% \mathrm{CI})=-0.20(-0.57$ to $0.17) ; P=0.446$ ) (Table 4).

\section{Discussion}

The purpose of this study was to investigate the influence of KT on trunk, hip and knee motions during a SLDL, SLVDJ, DLVDJ, and DLFJ tasks. The primary hypothesis was that KT would improve peak angles of trunk, hip and knee during SLDL, SLVDJ, DLVDJ and DLFJ. The present study results indicated that $\mathrm{KT}$ had an effect on the sum of knee valgus and lateral trunk lean, peak knee abduction angles during SLDL, and knee flexion during SLDL and SLVDJ tasks following a 72-h KT intervention. However, KT application showed no effect on SI during SLDL and SLVDJ tasks, or on knee and hip motions during

Table 4 Changes of limb symmetry index (SI) during SLDL and SLVDJ for knee abduction, knee flexion and hip flexion

\begin{tabular}{|c|c|c|c|c|c|c|}
\hline Symmetry Index (\%) & Task & $\begin{array}{l}\text { Without KT } \\
\text { (Baseline) }^{a}\end{array}$ & With $\mathrm{KT}^{a}$ & Pvalue & $\begin{array}{l}\text { Effect size }{ }^{\dagger} \text { and } 95 \% \text { Confidence } \\
\text { Interval (Lower limit -Upper limit) }\end{array}$ & $\begin{array}{l}\text { Change Relative } \\
\text { to Baseline }{ }^{\ddagger}(\%)\end{array}$ \\
\hline \multirow[t]{2}{*}{ Knee abduction } & SLDL & $0.4 \pm 4.8$ & $0.2 \pm 3.6$ & 0.850 & $-0.06(-0.42$ to 0.30$)$ & $\downarrow 51.2$ \\
\hline & SLVDJ & $1.0 \pm 6.5$ & $-1.1 \pm 3.5$ & 0.089 & $-0.61(-1.00$ to -0.21$)$ & $\downarrow 213$ \\
\hline \multirow[t]{2}{*}{ Knee flexion } & SLDL & $7.1 \pm 13.3$ & $7.7 \pm 16.6$ & 0.833 & $0.04(-0.32$ to 0.40$)$ & $\uparrow 9.2$ \\
\hline & SLVDJ & $1.1 \pm 11.0$ & $-1.1 \pm 10.7$ & 0.446 & $-0.20(-0.57$ to 0.17$)$ & $\downarrow 200.9$ \\
\hline \multirow[t]{2}{*}{ Hip flexion } & SLDL & $-13.4 \pm 17.0$ & $-6.1 \pm 21.1$ & 0.161 & $0.34(-0.03$ to 0.72$)$ & $\uparrow 54.2$ \\
\hline & SLVDJ & $-6.1 \pm 14.1$ & $-3.6 \pm 20.0$ & 0.615 & $0.13(-0.24$ to 0.49$)$ & $\uparrow 41.3$ \\
\hline
\end{tabular}

Abbreviation: ${ }^{a}$ Values stands for Mean \pm SD; SLDL Single-leg drop landing, SLVD J Single-leg vertical drop jump, KT Kinesio taping; $†$, Cohen's d; $\neq$, percent change relative to baseline ( $\downarrow$ decrease, $\uparrow$ increase) 
DLVDJ or DLFJ tasks in participants with high injury risk.

As a matter of fact, peak frontal plane knee angle has been linked to high-risk biomechanics associated with ACL injury, and studies also show that knee frontal plane kinematics are coupled with hip and trunk movement [4, 17, 34, 40]. Our results showed that peak knee abduction angle was reduced only in SLDL after KT application. This finding is consistent with a study conducted by Rajasekar et al. [35], who reported that KT on the gluteus medius improved activation, and reduced knee abduction angle during a double-leg drop jump test after a 72-h intervention. Indeed, using $\mathrm{KT}$ improves motor unit recruitment $[2,31]$. Therefore, $\mathrm{KT}$ might be added as an adjunct along with routine muscle strengthening to favourably modulate high-risk movement. After $72 \mathrm{~h}$, moreover, KT caused the sum of knee valgus and lateral trunk lean to be increased during SLDL, possibly by changes in knee abduction angle. The percentage changes to the baseline showed that after $72 \mathrm{~h} \mathrm{KT}$ the sum of knee valgus and lateral trunk lean and knee abduction angles decreased in the SLDL. These factors can reduce potential knee injury.

The basic KT mechanisms have not heretofore been fully investigated. It has been claimed that KT improves blood circulation and lymphatic flow, neurological activation, corrects weak muscle function, and enhances joint function [15, 20, 29, 31, 43, 45]. As KT stretches the skin, it stimulates cutaneous mechanoreceptors, which may cause physiological changes in the area and affect knee flexion angle [15, 20, 29, 31, 43, 45]. KT effects on muscle stretching appear after a relatively long time [31]. The longer use of KT application (72 h) possibly generated higher chronic stimulation of skin mechanoreceptors [31, 32]. Rebolledo et al. [31] revealed that KT may improve jump performance after $72 \mathrm{~h}$. However, it should not be overlooked that their study evaluated the jump height of a countermovement jump and squat jump, whereas the current study investigated a series of drop landings.

The results obtained from this study demonstrated that KT did not affect knee and hip angles during TLDVJ and DLFJ tasks. In fact, these results contradicted those observed in studies conducted by Limroongreungrat et al. [26], who showed that using ACL-KT technique can change DVJ task patterns in healthy participants. They reported that using the ACL-KT technique with a $75 \%$ tension reduces knee abduction angle during a DVJ. Furthermore, KT provides tactile stimulation [23, 44], although $\mathrm{KT}$ tactile inputs may not be strong enough to modulate muscle strength [13], and consequently, unable to moderate joint angles in healthy athletes during the double-leg landings of TLDVJ and DLFJ.
Decreased maximal flexion of the knee and hip are risk factors associated with ACL injury. Therefore, increasing knee and hip flexion during jump landing are components of successful injury prevention programs [25]. The present study showed that using KT increases knee flexion in SLDL and SLVDJ, which results in less strain within the ACL [14]. Similarly, Pelletier et al. [34] reported that KT tape increases knee and hip flexion angle during running, serving to better absorb impact forces. This finding may be explained by two theories. One theory is that KT results in increasing blood circulation to the taped area, thus affecting muscle and myofascial function and physiology. The other theory implies that the cutaneous mechanoreceptors are stimulated by $\mathrm{KT}$, and this stimulation may affect the joint angle [45]. The main mechanism whereby KT accomplishes these aims is purportedly the stimulation of cutaneous mechanoreceptors, thereby improving proprioception and joint position sense [26]. The possible increase in blood circulation [45], and eccentric hamstring muscle control affects knee flexion angle [11]. With KT applied on the quadriceps and hamstring muscles, greater knee flexion is facilitated, which then has a positive effect on hamstring function [2,31], This factor can theoretically be useful and effective for individuals with high ACL injury risk, who often perform difficult landings and have minimal sagittal plane knee displacement.

In contrary to the hypothesis, the results in this study indicate that $\mathrm{KT}$ does not affect maximal hip flexion in any landing test. Although no significant statistical increase was observed for maximum hip flexion angle during SLDL and SLVDJ, there was a small EF for dominant limb $(E S=-0.53)$, trivial $E F$ for non-dominant limb $(E S=-0.34)$ during SLDL and moderate EF for dominant limb $(E S=-0.82)$, and trivial $E F$ for non-dominant $\operatorname{limb}(E S=-0.31)$ during SLVDJ. In fact, this finding is different from the results reported by Pelletier et al. [34], a difference that might be attributable to task type, participant gender, or measurement tools. This factor may be related to the nature of KT technique, which is designed to imitate human skin. It does not stabilize the tissue, but permits full range-of-motion. Over-stretching of the KT may have hindered our ability to detect a statistically significant differences in hip flexion angles and lateral trunk lean between the KT conditions.

In addition, this study showed that the extent upon which KT affects SI during SLDL and SLVDJ was not statistically significant. The cause may be attributed to the equal effect of the KT on dominant and non-dominant legs. To the authors' knowledge, no study has explored SI after KT application during landing. Hence, it is not possible to compare the present results with 
previous findings. However, various studies indicate that $\mathrm{KT}$ increases motor unit recruitment in healthy individuals, which might justify biomechanical changes affected by the KT technique [2, 31, 44]. Furthermore, the results revealed that $\mathrm{KT}$ has no effect on lateral trunk lean angle. This finding is consistent with Yoshida et al. [45] who reported that lateral trunk lean is not affected by KT.

As in all studies, limitations have arisen that might affect the results. Specifically, this study population did not include a sham/placebo group. 2D motion analysis has been used to evaluate lower extremity kinematics during functional tasks in healthy and injured individuals. However, it is not without its flaws. Further studies through which electromyography and threedimensional (3D) motion analysis are used to detect changes in muscle excitability and joint kinematics are warranted. One of the weaknesses in this study is the fact that female participants were excluded. Future clinical trials with a female group and larger sample size should be performed to investigate the effect of KT on joint kinematics. Future studies are needed to assess the follow-up and long-term effects of KT to have strong conclusions.

\section{Conclusions}

In conclusion, a 72-h KT application may improve peak knee abduction angle, sum of knee valgus and lateral trunk motion during SLDL, and knee flexion during SLDL and SLVDJ. However, KT resulted in no significant effect on knee and hip joint angles during TLDVJ and DLFJ tasks, nor SI during SLDL and SLVDJ.

\section{Abbreviations}

ACL: Anterior Cruciate Ligament; KV: Knee Valgus; 2D: Two-Dimensional; SLVDJ: Single Leg Vertical Drop Jump; GRF: Ground Reaction Force; KT: Kinesio Taping; SLDL: Single-Leg Drop Landing; DLVDJ: Double leg Vertical Drop Jump; DLFJ: Double Leg Forward Jump; SLS: Single Leg Squat Test; AC: Acromioclavicular; ASIS: Anterior Superior Iliac Spine; GT: Greater Trochanter; SI: Symmetry Index; ES: Effect Size; 3D: Three-Dimensional.

\section{Acknowledgment}

We would like to express our deepest appreciation for valuable assistance and contribution of all the participants.

\section{Authors' contributions}

$\mathrm{BSH}, \mathrm{AL}, \mathrm{JH}$, and ENM contributed to the original idea, study design, and protocol, the conception of the work, conducting the study, data analysis, revising the drafting and editing of the article. $\mathrm{AL}, \mathrm{BSH}$, and $\mathrm{JH}$ contributed to the conception of the work, wrote, and editing of this article. All authors approved the final version of the article.

\section{Funding}

This research did not receive any specific grant from funding agencies in the public, commercial, or non-profit sectors.

\section{Declarations}

\section{Competing interests}

The authors declare no competing interests.

\section{Author details}

${ }^{1}$ Faculty of Physical Education and Sports Sciences, Kharazmi University, Tehran, Iran. ${ }^{2}$ Department of Biomechanics and Sports Injury, Faculty of Physical Education and Sports Sciences, Kharazmi University, Tehran, Iran. ${ }^{3}$ Health \& Human Performance Department, Graduate Athletic Training Program, University of Tennessee Chattanooga, Chattanooga, USA. ${ }^{4}$ Faculty of Physical Education and Sports Sciences, University of Tehran, Tehran, Iran.

Received: 1 December 2020 Accepted: 22 February 2021

Published online: 02 April 2021

\section{References}

1. Ageberg E, Bennell KL, Hunt MA et al (2010) Validity and inter-rater reliability of medio-lateral knee motion observed during a single-limb mini squat. BMC Musculoskelet Disord 11:265

2. Aydoğdu O, Sari Z, Yurdalan SU et al (2017) Clinical outcomes of kinesio taping applied in patients with knee osteoarthritis: a randomized controlled trial. J Back Musculoskelet Rehabil 30(5):1045-1051

3. Cohen J (1988) Statistical power analysis for the behavioral sciences. Lawrence Erlbaum Associates, New Jersey

4. Cruz A, Bell D, McGrath M et al (2013) The effects of three jump landing tasks on kinetic and kinematic measures: implications for ACL injury research. Res Sports Med 21(4):330-342

5. De Almeida Lins CA, Neto FL, de Amorim ABC et al (2013) Kinesio Taping ${ }^{\circledR}$ does not alter neuromuscular performance of femoral quadriceps or lower limb function in healthy subjects: Randomized, blind, controlled, clinical trial. Man Ther 18(1):41-45

6. De Jesus JF, De Almeida NA, Nakaoka GB et al (2016) Kinesio taping effect on quadriceps strength and lower limb function of healthy individuals: A blinded, controlled, randomized, clinical trial. Phys Ther Sport 18:27-31

7. De Jesus JF, dos Santos Franco YR, Nannini SB et al (2017) The effects of varied tensions of kinesiology taping on quadriceps strength and lower limb function. Int J Sports Phys Ther 12(1):85

8. Dingenen B, Malfait B, Nijs S et al (2015) Can two-dimensional video analysis during single-leg drop vertical jumps help identify noncontact knee injury risk? A one-year prospective study Clin Biomech 30(8):781-787

9. Dingenen B, Malfait B, Vanrenterghem J et al (2014) The reliability and validity of the measurement of lateral trunk motion in two-dimensional video analysis during unipodal functional screening tests in elite female athletes. Phys Ther Sport 15(2):117-123

10. Dix J, Marsh S, Dingenen B et al (2019) The relationship between hip muscle strength and dynamic knee valgus in asymptomatic females: A systematic review. Phys Ther Sport 37:197-209

11. Doğan E, Yilmaz AK, Özdal M et al (2019) Acute effects of reverse Kinesio Taping on knee muscle strength, fatigue index and $\mathrm{H} / \mathrm{Q}$ ratio in healthy subjects. Isokinetics and Exerc Sci 27(2):135-141

12. Fong C-M, Blackburn JT, Norcross MF et al (2011) Ankle-dorsiflexion range of motion and landing biomechanics. Athl Train 46(1):5-10

13. Fu TC, Wong AM, Pei YC (2008) Effect of Kinesio taping on muscle strength in athletes-a pilot study. J Sci Med Sport 11(2):198-201

14. Gehring D, Melnyk M, Gollhofer A (2009) Gender and fatigue have influence on knee joint control strategies during landing. Clin Biomech 24(1):82-87

15. Hadamus A, Grabowicz M, Wąsowski P (2018) Assessment of the Impact of Kinesiology Taping Application Versus Placebo Taping on the Knee Joint Position Sense. Preliminary Report Ortop Traumatol Rehabil 20(2):139-148

16. Halseth T, McChesney JW, DeBeliso M et al (2004) The effects of kinesio $\mathrm{TM}_{>}$taping on proprioception at the ankle. J Sports Sci Med 3(1):1 
17. Heebner NR, Rafferty DM, Wohleber MF et al (2017) Landing kinematics and kinetics at the knee during different landing tasks. Athl Train 52(12):1101-1108

18. Herrington L, Alenezi F, Alzhrani M et al (2017) The reliability and criterion validity of $2 \mathrm{D}$ video assessment of single leg squat and hop landing. J Electromyogr Kinesiol 34:80-85

19. Hewett TE, Myer GD, Ford KR et al (2005) Biomechanical measures of neuromuscular control and valgus loading of the knee predict anterior cruciate ligament injury risk in female athletes: a prospective study. Am J Sports Med 33(4):492-501

20. Inglés M, Serra-Añó P, Méndez ÀG et al (2019) Effect of Kinesio Taping and balance exercises on postural control in amateur soccer players: A randomised control trial. J Sports Sci 37(24):2853-2862

21. Cohen J (1988) Statistical power analysis for the behavioral sciences. Lawrence Erlbaum Associates, New Jersey

22. Koga H, Nakamae A, Shima Y et al (2010) Mechanisms for noncontact anterior cruciate ligament injuries: knee joint kinematics in 10 injury situations from female team handball and basketball. The Am J Sports Med 38(11):2218-2225

23. Konishi Y (2013) Tactile stimulation with kinesiology tape alleviates mus cle weakness attributable to attenuation of la afferents. J Sci Med Sport 16(1):45-48

24. Lam CLY, Fong SSM, Chung JWY et al (2018) Influence of pelvic padding and Kinesiology Taping on pain perception, kinematics, and kinetics of falls in female volleyball athletes. Gait Posture 64:25-29

25. Leppanen M, Pasanen K, Krosshaug T et al (2017) Sagittal Plane Hip, Knee, and Ankle Biomechanics and the Risk of Anterior Cruciate Ligament Injury: A Prospective Study. Orthop J Sports Med 5(12):2325967117745487

26. Limroongreungrat W, Boonkerd C (2019) Immediate effect of ACL kinesio taping technique on knee joint biomechanics during a drop vertical jump: a randomized crossover controlled trial. BMC Sports Sci Med Rehabil 11(11):32

27. Liu K, Qian J, Gao Q et al (2019) Effects of Kinesio taping of the knee on proprioception, balance, and functional performance in patients with anterior cruciate ligament rupture: A retrospective case series. Medicine 98(48):17956

28. Lyman KJ, Keister K, Gange K et al (2017) Investigating the effectiveness of kinesio ${ }^{\circledR}$ taping space correction method in healthy adults on patellofemoral joint and subcutaneous space. Int J Sports Phys Ther 12(2):250

29. Magalhães I, Bottaro M, Freitas JR, (2016) Prolonged use of Kinesiotaping does not enhance functional performance and joint proprioception in healthy young males: Randomized controlled trial. Braz J Phys Ther 20(3):213-22

30. Melo SA, Macedo LdB, Borges DT et al (2018) Effects of kinesio taping on neuromuscular performance and pain of individuals affected by patellofemoral pain: A randomized controlled trial. Physiother Theory Pract 1-11.

31. Mendez-Rebolledo G, Ramirez-Campillo R, Guzman-Muñoz E et al (2018) Short-term effects of kinesio taping on muscle recruitment order during a vertical jump: a pilot study. J Sport Rehabil 27(4):319-326

32. Nunes GS, De Noronha M, Cunha HS et al (2013) Effect of kinesio taping on jumping and balance in athletes: a crossover randomized controlled trial. J Strength Condition Res 27(11):3183-3189

33. Parreira P, Costa L, Takahashi R et al (2014) Kinesio Taping to generate skin convolutions is not better than sham taping for people with chronic nonspecific low back pain: a randomised trial. J Physiother 60(2):90-96

34. Pelletier A, Sanzo P, Kivi D et al (2019) The effect of patellar taping on lower extremity running kinematics in individuals with patellofemoral pain syndrome. Physiother Theory Pract 35(8):764-772

35. Rajasekar S, Kumar A, Patel J et al (2018) Does Kinesio taping correct exaggerated dynamic knee valgus? A randomized double blinded shamcontrolled trial. J Bodyw Mov Ther 22(3):727-732

36. Slomka B, Rongies W, Ruszczuk P et al (2018) Short-term effect of kinesiology taping on temperature distribution at the site of application. Res Sports Med 26(3):365-380

37. Stensrud S, Myklebust G, Kristianslund E et al (2011) Correlation between two-dimensional video analysis and subjective assessment in evaluating knee control among elite female team handball players. Br J Sports Med 45(7):589-595

38. Sugiyama T, Kameda M, Kageyama M et al (2014) Asymmetry between the Dominant and Non-Dominant Legs in the Kinematics of the Lower
Extremities during a Running Single Leg Jump in Collegiate Basketball Players. J Sports Sci Med 13(4):951-957

39. Tamura A, Akasaka K, Otsudo T et al (2016) Fatigue alters landing shock attenuation during a single-leg vertical drop jump. Orthop J Sports Med 4(1):2325967115626412

40. Taylor JB, Ford KR, Schmitz RJ et al (2017) Biomechanical differences of multidirectional jump landings among female basketball and soccer players. J Strength Cond Res 31(11):3034-3045

41. Ugalde V, Brockman C, Bailowitz Z et al (2015) Single leg squat test and its relationship to dynamic knee valgus and injury risk screening. PMR 7(3):229-35

42. Ward RE, Fong Yan A, Orishimo KF et al (2019) Comparison of lower limb stiffness between male and female dancers and athletes during drop jump landings. Scand J Med Sci Sports 29(1):71-81

43. Williams S, Whatman C, Hume PA et al (2012) Kinesio taping in treatment and prevention of sports injuries. Sports Med 42(2):153-164

44. Yam ML, Yang Z, Zee BC et al (2019) Effects of Kinesio tape on lower limb muscle strength, hop test, and vertical jump performances: a metaanalysis. BMC Musculoskelet Disord 20(1):212

45. Yoshida A, Kahanov L (2007) The effect of kinesio taping on lower trunk range of motions. Res Sports Med 15(2):103-112

\section{Publisher's Note}

Springer Nature remains neutral with regard to jurisdictional claims in published maps and institutional affiliations.

\section{Submit your manuscript to a SpringerOpen ${ }^{\circ}$ journal and benefit from:}

- Convenient online submission

- Rigorous peer review

- Open access: articles freely available online

- High visibility within the field

- Retaining the copyright to your article

Submit your next manuscript at springeropen.com 